\title{
Interior Design Students' Attitudes towards Environmental Sustainability
}

\author{
Donia M. Bettaieb \\ Department of Interior Design and Furniture, King Abdulaziz University, Jeddah, KSA \\ Email: doniamalek2@gmail.com
}

How to cite this paper: Bettaieb, D. M (2020). Interior Design Students' Attitudes towards Environmental Sustainability. Art and Design Review, 8, 31-48. https://doi.org/10.4236/adr.2020.81003

Received: December 16, 2019

Accepted: February 14, 2020

Published: February 17, 2020

Copyright (c) 2020 by author(s) and Scientific Research Publishing Inc. This work is licensed under the Creative Commons Attribution International License (CC BY 4.0).

http://creativecommons.org/licenses/by/4.0/ (c) (i)

Open Access

\begin{abstract}
This study aims to investigate the attitudes of students towards environmental sustainability. To identify their level of concern for the environment and the impact of the academic year on their attitudes towards environmental sustainability, a quantitative approach was adopted using a cross-sectional survey. A questionnaire was distributed to $(\mathrm{N}=78)$ interior design students at King Abdulaziz University (KAU) in Jeddah. Interior design students responded to a three-part survey including demographic characteristics, ecology and environmental sustainability, and comments. The results revealed that students' level of interest in the environment was moderate and that their attitudes were generally positive and moderately pro-environmental. In general, there was understanding and awareness among students regarding the problems related to nature as well as a lack of accuracy of the information they obtained. Although the results also showed students' understanding of the use of sustainable products and solutions in interior design scenarios, there was a clear lack of actual uses of these products and solutions in student projects, and there was a gap between what students said about what they were doing in their project and what they actually applied in their design projects. Finally, the results indicated that the attitudes and perceptions of the students surveyed regarding environmental sustainability did not actually depend on the specialization variable or the level of the study. Through a deeper application of the fundamentals of responsible design, it is shown that enthusiastic and conscientious students can be guided towards environmental sustainability and achieve exciting results. The results of this study will help to raise awareness of interior design educators about students' attitudes towards environmental sustainability. The results also illustrate the importance of following the application of sustainability requirements in interior design projects and of not limiting student exposure.
\end{abstract}

\section{Keywords}

Interior Design, Sustainability, Education, Environment, Ecology, Attitudes, 
Cognition, Behavior, Practice

\section{Introduction}

In recent years, the practice of interior design has undergone an essential change through design strategies primarily focused on producing healthy and sustainable environments in which people can live, work and play (Bonda \& Sosnowchick, 2006; Hayles, 2015; Demirkan \& Afacan, 2018). Nevertheless, there is a limited number of sustainable choices in actual design practice by interior designers (Kang \& Guerin, 2009; Hayles, 2015). Some studies have emphasized the need to change core values and perceptions so that long-term changes can become effective (Mate, 2009). Building pro-environmental behaviours is essential to reducing negative environmental impacts and moving towards a more sustainable future.

The role of higher education is important for producing professionals capable of protecting the environment (Şahin \& Erkal, 2017), and within this framework, higher education should aim to provide students with the attitudes, values and behaviours necessary for the development of local and global values (Summers et al., 2000). The integration of the knowledge, skills, attitudes and values that students obtain through their undergraduate studies in their professional and personal lives, as well as in their environment, is one of the key functions they are supposed to enact in their communities and careers after graduation (Şahin \& Erkal, 2017). Education is a critical factor in public knowledge of the environment (Polonsky et al., 2011; Paço \& Lavrador, 2017). Education may also be able to address the limitations mentioned above, and education should be more involved in the local context and meet the community's needs for the production of participatory scientific knowledge (Brundiers et al., 2010).

Design professionals have a major responsibility in paving the way for sustainability (Ruff \& Olson, 2009). Educators and early practitioners of interior design realized that our responsibility to the planet and its population is to meet the needs and diverse expectations of people living in the environments we design. We are now aware that sustainability in interior design is more than only being responsible for selecting "ecological" materials; it is also necessary to match them with the client's values and vision (McCoy, 2012). Therefore, our greatest concern should be to accustom interior design students to the use of sustainable products and methods; moreover, there is no subject or project in interior design that is not directly related to sustainability (McCoy, 2012). However, this strategy requires further efforts to make the interior design industry adopt fewer environmentally harmful practices (Ruff \& Olson, 2009).

In this regard, the Council for Interior Design Accreditation (CIDA) has specifically required academic programs to adopt sustainability education in their 
curriculum in addition to the setting professional standards (2018) to form a standard (14) related to "ecosystems and comfort" whereby "interior designers use the principles of acoustics, thermal comfort and indoor air quality in relation to environmental impact and human well-being". CIDA explained that this standard "allows graduates to contribute to the development of appropriate strategies to ensure well-being, comfort and performance in the interior environments" and will make them more aware of the environmental impact of their design decisions (CIDA, 2019).

Sustainable design, environmental design, eco-design, green design, etc., are expressions designating a design that respects the environment (El-Zeiny, 2012; Honadi, 2014). Sustainable design has become a leading movement in the field of architecture and design, as it concerns a worldview and philosophy that seeks to maximize the quality of the built environment while minimizing and eradicating the negative effects on the natural environment (Honadi, 2014). Sustainable design reduces the impact on the environment in terms of location selection, water use, energy consumption and selection of materials (Rider, 2005; Bacon, 2011).

The aim of designing a sustainable interior environment is to integrate the design process framework as a general approach that changes according to the needs of designers with the identification, classification and regulation of relevant data requirements (Demirkan \& Afacan, 2018). Some researchers have confirmed that a successful project is one that integrates sustainability at every stage of the design process, from implementation to post-occupancy (Winchip, 2007; Bacon, 2011). Sustainable interior design characteristics vary and are of varying importance. Therefore, one must follow certain methods to improve options when it is important for the interior designer to collaborate with users (Demirkan \& Afacan, 2018) in addition to combining user interests, cost factors, time restraints and technology. Here, sustainability assigns an additional factor to the formation of the project (Bacon, 2011).

The aspects of sustainable interior design mainly include energy consumption, materials and the interior environmental quality (IEQ) (i.e., the internal conditions of the building, such as air quality, daylight access, openings on the exterior, etc.), water use and waste management (Khaleel, 2013). A sustainable built environment is the product of efforts to effectively integrate site, energy, water and materials as well as resources and the interior environment (Demirkan \& Afacan, 2018). Interior designers take the lead in selecting materials and achieving low-consumption energy systems (Khaleel, 2013). Conceptual approaches to sustainable design proposals are often linked to the use of local materials, building guidance, passive solar systems, natural ventilation and lighting (Çeliker, 2017). In this context, Bacon provides examples of sustainable design practices, identifying the importance of local specifications for manufactured materials or fast renewable materials and/or sustainable materials (Bacon, 2011). 
The following (Figure 1) is a summary of a mind map inspired by the table "Key references for the effective use of the environment" designed by Demirkan \& Afacan (2018). This mind map illustrates the essential foundations on which the design of sustainable interior environments should be based.

According to Giannelloni's broad and very abstract definition, behaviour can be described as ecological and allows one, directly or indirectly, to avoid the degradation of the natural environment or to contribute to its protection and/or repeated rehabilitation (Giannelloni, 1998). In other words, behaviour is ecological in regard to positive cognitive and behavioural responses to environmental problems, including environmental pollution, the population explosion, the reduction of natural resources, the extinction of some species of animals and plants, etc. In this context, Giannelloni finds that humans as living organisms are usually embedded in nature and that each of our actions may have direct and somewhat immediate consequences on nature. This view emphasizes that our daily behaviours, which are harmless as consumers as well as citizens, are not exempt from this situation and aim to be environmental (Giannelloni, 1998).

In this overall context, analysis of the knowledge, attitudes and behaviour of university students regarding the environmental field is particularly important, as these students represent the most important decision makers of the future (Paço \& Lavrador, 2017; Al-Naqbi \& Alshannag, 2018). Moreover, graduating designers who enter the profession today, which is saturated with the principles and practices of sustainability, in most cases do not have the appropriate tools and information to accomplish the task (McCoy, 2012). Thus, understanding the

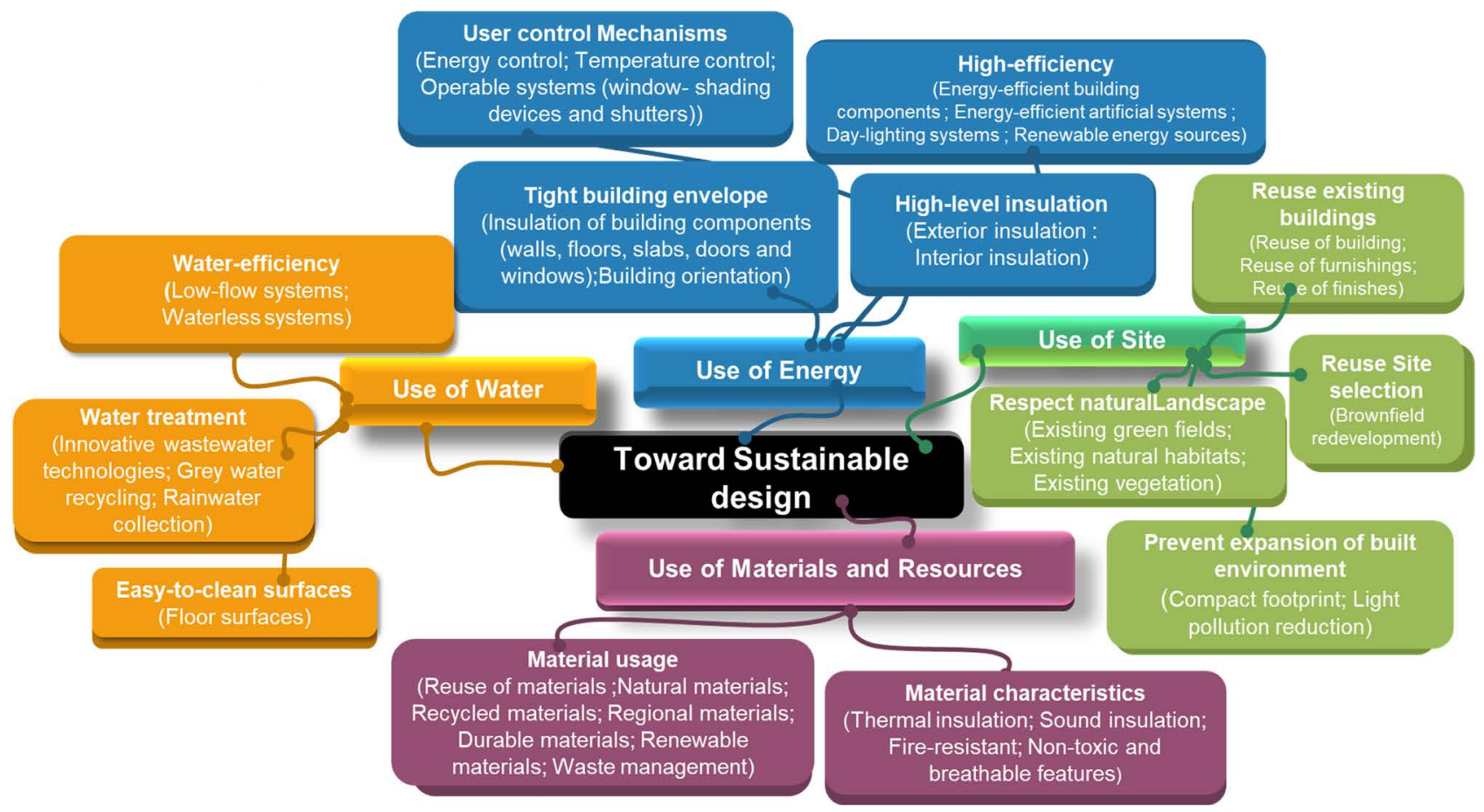

Figure 1. Towards the design of a sustainable interior environment, Demirkan \& Afacan, 2018. 
situation of students' attitudes towards environmental issues will support the use of sustainable methods and products and facilitate the design of appropriate education (Ruff \& Olson, 2009).

Several studies have been conducted on the attitudes of students towards sustainability (Ruff \& Olson, 2009; Şahin \& Erkal, 2017), on the attitudes of interior designers regarding sustainable interior design practices (Bacon, 2011), on the variables affecting student attitudes (Beery, 2013), and on the impact of interior design education on attitudes towards sustainable design and collaborative learning (Gale et al., 2014). Some researchers have revealed a lack of studies on student attitudes towards sustainability (Ruff \& Olson, 2009; Şahin \& Erkal, 2017).

Ruff \& Olson asked 95 interior design students to assess their level of interest for the environment. The results were measured by an adapted version of the new environmental model (NEP) scale, which determines their level of confidence in applying practices of sustainable interior design in projects. The results showed that despite these students' environmental sustainability education, many were convinced that nature could be continually renewed. Researchers have examined the responsibility of educators to prepare for sustainability rather than assume that students will easily embrace this concept by themselves in their design projects (Ruff \& Olson, 2009). This conclusion underscores the need for empirical evidence to support the effectiveness of sustainable design education.

Bacon studied the attitudes of the interior designers from the practice of sustainable interior design and the obstacles to be overcome to eliminate environmental problems. The queries were categorized into five issues: conserving land resources, encouraging the use of sustainable practices in interior design, and improving the health of buildings, populations, and the direction and openings for use. The difficulties with use of sustainable practices in interior design were founded on three classifications: project skills, transition to sustainability, and knowledge and skills associated with sustainable design. In general, the attitudes to sustainable interior design practices were positive. There was a correlation between the attitudes and the difficulties expected, suggesting that a positive attitude contributed, in part, to overcoming the difficulties associated with sustainable interior design.

Beery performed a study of the sustainability awareness of university students to evaluate their participation in the pro-ecological and prosocial components of sustainability. By analysing what have suggested by participants in interviews, Beery noted that the activities in which students participated throughout their careers affected their vision of sustainability both positively and negatively. The results recommend that education have to be used as a means of raising awareness and promoting positive behaviours (Beery, 2013).

Taking a social constructivist approach, Gale et al. studied the difference in attitudes towards collaborative learning between interior design students who belonged to two different levels of education (lower and higher) and the potential 
impact of interior design teaching on their attitudes towards design via sustainable and collaborative learning. The results suggested that top-level students had more "positive attitude" towards sustainable design than lower-level students. The researchers noted a relationship between the two variables. Nonetheless, the results showed that top-level students had less favourable positions regarding collaborative learning than lower-level students. From this standpoint, researchers have emphasized the need to focus on collaborative learning alongside sustainable design training in the field of interior design education to enhance the professional success of future students (Gale et al., 2014).

Şahin \& Erkal investigated the attitudes towards environmental sustainability between two different groups (students who studied "child development" and those who studied "social work") through five dimensions: 1) environmental issues; 2) "insensitivity to environmental problems"; 3) "recycling for environmental Sustainability"; 4) "negative thinking about a sustainable environment"; and 5) "the importance of a sustainable environment". The results exposed that students studying "child development" "were more environmentally conscious" than those studying "social work" and that their knowledge and level of education were clearly based on environmental awareness. Researchers have revealed that rapid changes in environmental knowledge should be raised as a challenge and that these changes should be included in university programs (Şahin \& Erkal, 2017).

\section{Research Methodology}

\section{Research Objectives}

1) To achieve a comprehensive understanding of what constitutes sustainable design practices in interior design projects.

2) To investigate the attitudes of students towards environmental sustainability by identifying their level of interest in the environment (Ruff \& Olson, 2009; Şahin \& Erkal, 2017) as measured by a revised version of the NEP and to investigate what has been identified regarding their level of confidence in applying sustainable design practices in interior design projects (Ruff \& Olson, 2009).

3) To investigate impact of the academic year on interior design on students' attitudes towards sustainable design (Ruff \& Olson, 2009; Gale et al., 2014).

\section{Search Questions}

1) What is the level of interest in the environment of interior design students at KAU?

2) To what extent do interior design students at KAU use sustainable products and solutions in interior design scenarios?

3) What is the potential impact of different levels of interior design education on students' attitudes that can be adopted for sustainable design? In other words, are there statistically significant differences between the average responses of interior design students at KAU regarding their level of interest in the environment and the extent to which they use sustainable products and solutions in in- 
terior design scenarios according to their the year level?

A field study was carried out using the questionnaire adopted by Ruff \& Olson (2009), with some modifications, to ensure the effectiveness of the questionnaire according to the context of the study. In phase one, the questionnaire was presented to a group of colleagues in the field of interior design and statistics. Then, in phase two, the questionnaire was given to a group of students to answer. These two phases made it possible to verify the clarity of the language and presentation. Through these phases, some suggestions were made regarding both the large number of questions and the resolution structure. Based on the comments, some questions about pro-environmental behaviours were removed and merged with questions related to the relationship between environmental sustainability and interior design.

\section{Data collection procedures}

The data were collected through an online questionnaire in classrooms that provided questions in two languages (Arabic and English). The questionnaire was sent to all interior design students enrolled in KAU in Jeddah during the first semester of the 2018-2019 academic year.

The target sample of this study was $(n=87)$ female students representing the population of interior design students at King Abdulaziz University. A stratified sample was applied based on the year level (level 3-Studio 1-first year of specialization; level 5-Studio 3-second year of specialization; level 7-Studio 5-third year of specialization). The year level variable can affect the level of knowledge that prevails and shape students' attitudes.

\section{Instrumentation and development of the questionnaire}

The questionnaire included three sections: 1) demographic characteristics, 2) ecology and environmental sustainability and 3) comments (Figure 2). In the first section, participants were asked to provide additional demographic social information useful for analyses, such as age, nationality, admission to the program (competition, equivalence), level of specialization, studio level $(1,3,5)$, and the regularity of development in accordance with the programme plan (regular and irregular).

Ecological attitude was measured in the first axis of the second section of the questionnaire (15 questions) through a modified version of the new NEP environmental model (New Ecological Paradigm) (Dunlap et al., 2000).

In measuring the degree of approval of an environmental vision of the world, an NEP survey was prepared using its original 1978 version to compare the environmental orientations of American students (Ruff \& Olson, 2009). Dunlap et al. have designed a revised version of the NEP scale in which 15 elements are grouped together as a "new environmental model Scale" (Dunlap et al., 2000). The revised NEP is an improved measurement tool compared to the first scale, as it covers the basic aspects of ecological vision (Dunlap et al., 2000) and does so more comprehensively. Some researchers consider it to be the most appropriate measure to use as a predictive tool for environmental attitudes (Dunlap et al., 


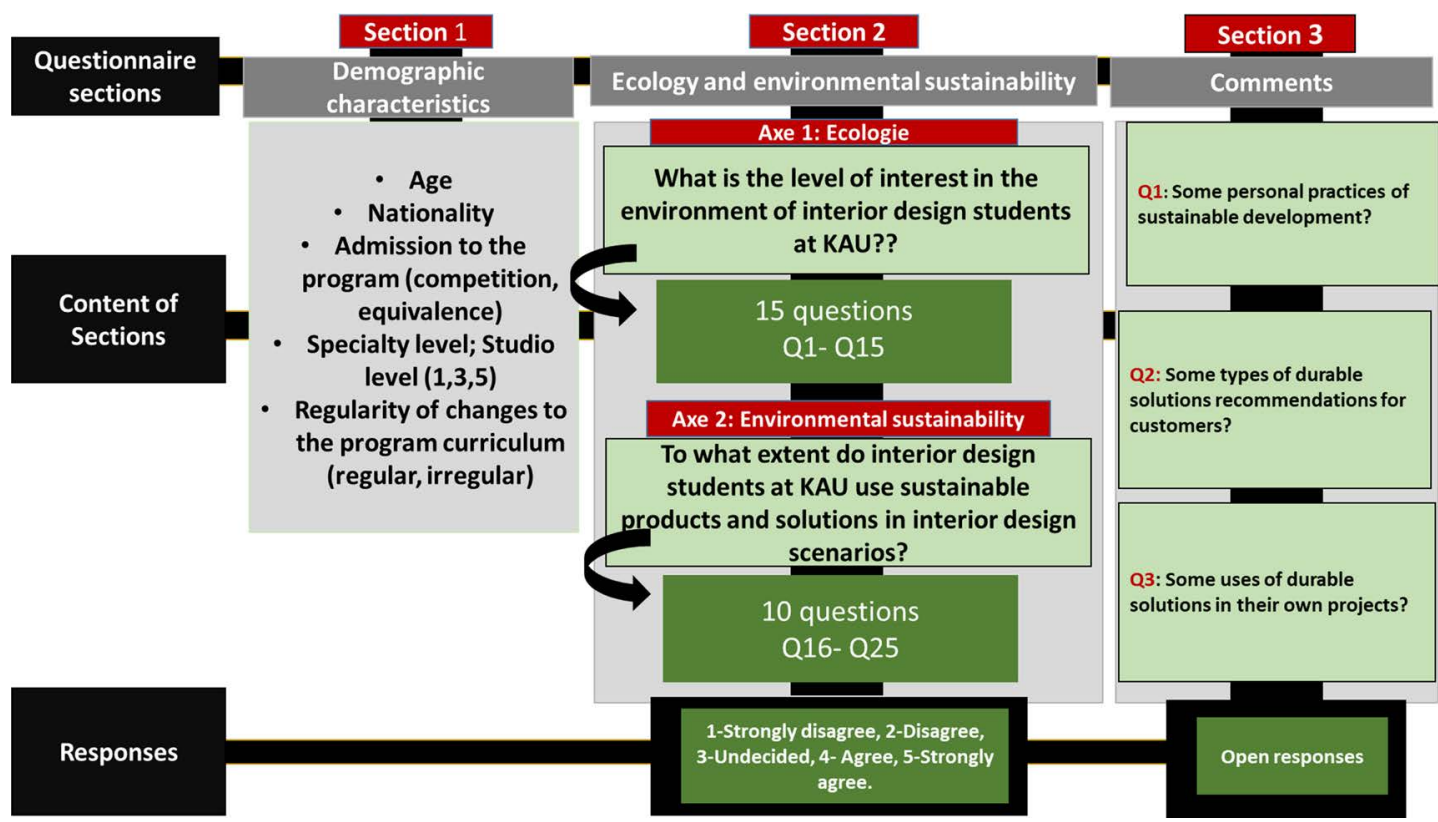

Figure 2. Structure and development of the questionnaire.

2000; Ruff \& Olson, 2009; Harraway et al., 2012).

Participants were asked to assess their level of approval for each term on a five-point Likert scale. The responses were then converted according to the NEP rate, with the highest overall scores pointing to a more pro-environmental (environmentally friendly) attitude on a scale of 1 to 5 . In addition, students' attitudes towards environmental sustainability were measured during the second axis of the second section of the questionnaire (10 questions). Respondents assessed the terms using the 5-point Likert method.

During the third section of the open questions (5 questions) titled "Comments", respondents commented on environmental sustainability 1) by mentioning some personal practices of environmental sustainability, 2) by providing some types of recommendations for durable solutions to their presumed clients and 3) by mentioning some of their uses for sustainable solutions during their design projects.

This section of the comments was evaluated by the researcher to determine the correct answers, adding "Yes" or "No" if the participant made a valid comment on the questionnaire. We then collected the number of negative answers that related to leaving the answer blank or answering "I don't know" as well as similar responses, such as "I can't answer", "no comment”, or "I haven't studied that yet".

\section{Data Analysis Procedures}

To achieve the objectives of the study, the Statistical Package for Social Sciences computer program (SPSS) was used to analyse the data and obtain results as follows:

- Repetitions and percentages to describe the properties of the study sample.

- Means and standard deviations to identify the responses of the sample to 
each of the questionnaire terms.

- Mono variance analysis (one-way ANOVA) to determine the significance of differences between more than two separate groups.

\section{Study Sample}

Table 1 shows the distribution of the characteristics of the students who answered the questionnaire: 78 of the 87 target students in the field of interior design at King Abdulaziz University. The participants represented $90 \%$ of the total number of the target population, with $84.6 \%$ Saudis and $26.4 \%$ different Arab nationalities (23.1\% Syrian, 29.5\% Palestinian, 11.5\% Egyptian and 14.1\% Yemeni). The age range of respondents was from 19 to 25 years, with an average age of 22 years and the most common age being 21 years.

The results showed that $97.4 \%$ of all these students were accepted according to their requests for the annual specialty exam and $97.4 \%$ according to the program plan. The results also revealed that compared to the total number of students responding (78), 35.9\% were registered at level 3-Studio 1-first year of specialization, $34.6 \%$ at level 5-Studio 3 -second year of specialization, and $29.5 \%$ at level 7 -Studio 5 -third year of specialization. Note that these students had varying levels of knowledge and skills relating to different aspects of environmental sustainability because they belonged to different levels of Interior design studios.

\section{Limitations/implications of the search}

First, the participating students were female and represented the total number of interior design students at KAU. Future studies should include male samples from similar disciplines such as architecture.

Second, the participating students were State university students. Although the university is an important university in the country, additional studies should include samples from other government and private institutions.

Table 1. Distribution of students according to their individual characteristics.

\begin{tabular}{|c|c|c|c|}
\hline Variables & Groups & n/ students & Percentage $\%$ \\
\hline \multirow{7}{*}{ Age } & 19 & 11 & 14.1 \\
\hline & 20 & 18 & 23.1 \\
\hline & 21 & 23 & 29.5 \\
\hline & 22 & 9 & 11.5 \\
\hline & 23 & 11 & 14.1 \\
\hline & 24 & 4 & 5.1 \\
\hline & 25 & 2 & 2.6 \\
\hline \multirow{5}{*}{ Nationality } & Saudi & 66 & 14.1 \\
\hline & Syrian & 3 & 23.1 \\
\hline & Palestinian & 4 & 29.5 \\
\hline & Egyptian & 1 & 11.5 \\
\hline & Yemeni & 4 & 14.1 \\
\hline \multirow{3}{*}{ Year of specialty } & First & 28 & 35.9 \\
\hline & Second & 27 & 34.6 \\
\hline & Third & 23 & 29.5 \\
\hline \multirow{2}{*}{ Regularity of changes to the program curriculum } & Regular & 76 & 97.4 \\
\hline & Irregular & 2 & 2.6 \\
\hline \multicolumn{2}{|l|}{ Total } & 78 & 100 \\
\hline
\end{tabular}




\section{Results}

This section presents the results of the study derived from answering the questions. To answer the first question concerning the measurement of the interest of interior design students at KAU in the environment, means and standard deviations were calculated and the sample's approval grades were computed on environment-related terms; the results are presented in Table 2.

The results are presented in descending order, from the largest mean to the smallest mean, indicating a less positive attitude. Table 2 shows that the mean of the degree of approval of the sample in terms of the interest of interior design students at KAU in the environment ranged from 1.55 to 4.86 , where statement (6), that "The earth has plenty of natural resources if we only learn how to develop them", obtained the highest average with a mean value of 4.86 , while the negative statement (5) that "Humans are severely abusing the environment" received the lowest average with a mean value of 1.55. The table also shows that the total number of statements has a moderate level (3.21) and an average approval level, which shows that the interest of interior design students at KAU in the environment is moderate.

Table 3 shows the precise mean responses of the sample to the degree of approval.

The results of the second question regarding the measurement of the use of

Table 2. Means and standard deviations of responses regarding the interest of interior design students at KAU in the environment.

\begin{tabular}{|c|c|c|c|c|c|}
\hline No. & Statements & Means & SD & Level & Order \\
\hline 6 & $\begin{array}{l}\text { The earth has plenty of natural resources if we only } \\
\text { learn how to develop them. }\end{array}$ & 4.86 & 0.386 & V. large & 1 \\
\hline 7 & $\begin{array}{l}\text { Plants and animals have as much right as humans to } \\
\text { exist. }\end{array}$ & 4.77 & 0.454 & V. large & 2 \\
\hline 15 & $\begin{array}{l}\text { If things continue on their present course, we will soon } \\
\text { experience a major ecological catastrophe. }\end{array}$ & 4.44 & 0.731 & V. large & 3 \\
\hline 9 & $\begin{array}{l}\text { Despite their special abilities, humans are still subject } \\
\text { to the laws of nature. }\end{array}$ & 3.85 & 0.869 & Large & 4 \\
\hline 4 & $\begin{array}{l}\text { Human ingenuity will ensure that we do not make the } \\
\text { earth unliveable. }\end{array}$ & 3.37 & 1.152 & Moderate & 5 \\
\hline 11 & $\begin{array}{l}\text { The earth is like a spaceship with very limited room } \\
\text { and resources*. }\end{array}$ & 3.37 & 1.082 & Moderate & 6 \\
\hline 1 & $\begin{array}{l}\text { We are approaching the limit of the number of people } \\
\text { the earth can support. }\end{array}$ & 3.32 & 0.904 & Moderate & 7 \\
\hline 8 & $\begin{array}{l}\text { The balance of nature is strong enough to cope with the } \\
\text { impacts of modern industrial nations. }\end{array}$ & 3.32 & 1.099 & Moderate & 8 \\
\hline 2 & $\begin{array}{l}\text { Humans have the right to modify the natural } \\
\text { environment to suit their needs. }\end{array}$ & 3.27 & 1.181 & Moderate & 9 \\
\hline 3 & $\begin{array}{l}\text { When humans interfere with nature, it often produces } \\
\text { disastrous consequences*. }\end{array}$ & 2.60 & 1.085 & Moderate & 10 \\
\hline 10 & $\begin{array}{l}\text { The so-called "ecological crisis" facing humankind has } \\
\text { been greatly exaggerated. }\end{array}$ & 2.55 & 1.147 & Small & 11 \\
\hline 13 & $\begin{array}{l}\text { The balance of nature is very delicate and easily } \\
\text { upset*. }\end{array}$ & 2.46 & 0.963 & Small & 12 \\
\hline 14 & $\begin{array}{l}\text { Humans will eventually learn enough about how nature } \\
\text { works to be able to control it*. }\end{array}$ & 2.46 & 0.801 & Small & 13 \\
\hline 12 & Humans are meant to rule over the rest of nature. & 2.00 & 0.883 & Small & 14 \\
\hline 5 & Humans are severely abusing the environment. & 1.55 & 0.595 & V. Small & 15 \\
\hline & Total & 3.21 & 0.230 & Moderate & \\
\hline
\end{tabular}


sustainable products and solutions in interior design scenarios, the calculation of mean and standard deviations and the grading of the degree of approval of the sample in terms of the use environmental solutions and methods in interior design scenarios are presented in Table 4. In the second phase, open responses were considered and categorized.

Table 4 shows that the mean of the degrees of approval of the sample in terms of the use of sustainable products and solutions in interior design scenarios of the environment ranged from 3.01 to 4.59 , where statement (20) "If I had the opportunity, I would build my home using sustainable methods" obtained the highest average with a mean value of 4.59 , while statement (24) "I have the knowledge to justify the added cost of sustainable features to clients" received the lowest average with a mean value of 3.01. The table also shows that the total statements had an average value of 4.12 and a significant degree of approval, which indicates that the use of sustainable products and solutions in interior design scenarios is highly significant. Regarding the opening answers, $83.3 \%$ of respondents answered the first question concerning personal environmental sustainability practices, while $17.7 \%$ did not answer this question. The results revealed three categories of practice:

- Daily practices related to the recycling, reduction and reuse of various materials and products (plastic bags, waste, cans, paper, etc.), which reduces energy

Table 3. Average responses of sample members to the degree of approval.

\begin{tabular}{|c|c|}
\hline Mean & Level \\
\hline $4.2<$ & V. large \\
\hline From 3.4 to 4.2 & Large \\
\hline From 2.6 to 3.4 & Moderate \\
\hline From 1.8 to 2.6 & Small \\
\hline$<1.8$ & V. Small \\
\hline
\end{tabular}

Table 4. Means and standard deviations of responses to the use of sustainable products and solutions in interior design scenarios.

\begin{tabular}{|c|c|c|c|c|c|}
\hline No. & Statements & Means & SD & Level & Order \\
\hline 20 & $\begin{array}{l}\text { If I had the opportunity, I would build my home using } \\
\text { sustainable methods. }\end{array}$ & 4.59 & 0.521 & V. large & 1 \\
\hline 16 & $\begin{array}{l}\text { I feel I could accomplish an interior design project using } \\
\text { sustainable methods. }\end{array}$ & 4.44 & 0.594 & V. large & 2 \\
\hline 25 & $\begin{array}{l}\text { I think 'Cradle to Cradle' should be required in an interior } \\
\text { design program. }\end{array}$ & 4.40 & 0.589 & V. large & 3 \\
\hline 17 & $\begin{array}{l}\text { I feel I could accomplish an interior design project using } \\
\text { sustainable products. }\end{array}$ & 4.33 & 0.715 & V.Large & 4 \\
\hline 23 & $\begin{array}{l}\text { If asked, I could direct a client to a sustainable functional } \\
\text { design. }\end{array}$ & 4.24 & 0.706 & V. large & 5 \\
\hline 22 & $\begin{array}{l}\text { If asked, I could direct a client to a sustainable building in } \\
\text { commercial design. }\end{array}$ & 4.17 & 0.728 & Large & 6 \\
\hline 21 & $\begin{array}{l}\text { If asked, I could direct a client to a sustainable building in } \\
\text { residential design. }\end{array}$ & 4.14 & 0.768 & Large & 7 \\
\hline 18 & $\begin{array}{c}\text { I feel green organizations/certification will solve } \\
\text { environmental issues in design. }\end{array}$ & 4.03 & 0.738 & Large & 8 \\
\hline 19 & $\begin{array}{l}\text { I feel there is no reason that using sustainable practices in } \\
\text { design is optional. }\end{array}$ & 3.81 & 0.898 & Large & 9 \\
\hline 24 & $\begin{array}{l}\text { I have the knowledge to justify the added cost of } \\
\text { sustainable features to clients. }\end{array}$ & 3.01 & 0.890 & Moderate & 10 \\
\hline & Total & 4.12 & 0.429 & Large & \\
\hline
\end{tabular}


and water consumption (enjoy the climate and natural lighting, and make sure to turn off the light when leaving the room or home, etc.).

- The expected practices in the interior design studio, which are often associated with the choice of environmentally friendly materials and theoretical solutions that reduce electricity and energy consumption, as well as of environmentally compatible design options.

- Social practices that publish information, inform society of the importance of environmental sustainability and choose environmentally friendly materials.

As for the second question regarding the recommendations of sustainable solutions for users, $14.2 \%$ of the participants did not answer the question. The percentage of respondents who did answer the question was $85.8 \%$. The results indicate that the recommendations for reliable solutions for clients were related to the following five concepts:

- Energy (thermal insulation, renewable energy, solar energy, solar panel, LED lighting, etc.).

- Use of water (use of alternatives to wastewater and economy in consumption, etc.).

- Design (integration of the external environment at home in addition to green surfaces, allocation of waste organizing places, study of environmental control systems according to the requirements of the environment, utilization of lighting and natural ventilation, use of local resources, use of sustainable raw materials, concept of expanded windows in favour of natural lighting, etc.).

- Materials (durability of the materials, the nature of the material: non-toxic, natural to facilitate the recycling process, the raw materials used and the methods of treatment, etc.).

- Furniture (recycling furniture).

With regard to the use of sustainable solutions in their own design projects, the results revealed that almost half of the respondents $(42.3 \%)$ did not answer the question, while only $58.7 \%$ indicated some use of sustainable solutions in their own projects.

The mean and standard deviations of the responses of the interior design students at KAU were calculated according to their level of interest in the environment and the extent to which they used sustainable products and solutions in interior design scenarios depending on the year-level variable; the results were as follows Table 5 .

We performed an analysis of single variance to determine the significance of the differences between the responses of students about their level of interest in the environment and the extent to which they use of sustainable products and solutions in interior design scenarios.

Table 6 illustrates that the values of the significance levels were greater than 0.05 in all axes, meaning that there were no statistically significant differences among the averages of the responses of interior design students at KAU regarding their level of interest in the environment and that the extent of their use of 
Table 5. Means and standard deviations of students' responses on their level of interest in the environment and the use of sustainable products and solutions in interior design scenarios depending on the year level.

\begin{tabular}{|c|c|c|c|c|}
\hline Axis & Year of specialty and studio level & Number of students & Mean & SD \\
\hline \multirow{3}{*}{$\begin{array}{l}\text { Level of interest in the } \\
\text { environment }\end{array}$} & $\begin{array}{c}\text { Second year } \\
\text { 1st year of specialty } \\
\text { STUDIO 1 }\end{array}$ & 28 & 3.25 & 0.214 \\
\hline & $\begin{array}{c}\text { Third year } \\
\text { 2nd year of specialty } \\
\text { STUDIO } 3\end{array}$ & 27 & 3.20 & 0.245 \\
\hline & $\begin{array}{c}\text { Fourth year } \\
\text { Year of graduation diploma }+ \text { Professional } \\
\text { internship } \\
\text { STUDIO 5 }\end{array}$ & 23 & 3.19 & 0.237 \\
\hline \multirow{3}{*}{$\begin{array}{l}\text { Use of sustainable } \\
\text { products and solutions in } \\
\text { interior design scenarios }\end{array}$} & $\begin{array}{l}\text { Second year } \\
\text { 1st year of specialty } \\
\text { STUDIO } 1\end{array}$ & 28 & 3.98 & 0.471 \\
\hline & $\begin{array}{c}\text { Third year } \\
\text { 2nd year of specialty } \\
\text { STUDIO 3 }\end{array}$ & 27 & 4.23 & 0.396 \\
\hline & $\begin{array}{c}\text { Fourth year } \\
\text { Year of graduation diploma }+ \text { Professional } \\
\text { internship } \\
\text { STUDIO 5 }\end{array}$ & 23 & 4.14 & 0.382 \\
\hline
\end{tabular}

Table 6. Test analysis.

\begin{tabular}{|c|c|c|c|c|c|c|}
\hline Axis & $\begin{array}{l}\text { Source of } \\
\text { contrast }\end{array}$ & $\begin{array}{c}\text { Total number } \\
\text { of squares }\end{array}$ & $\begin{array}{l}\text { Degrees of } \\
\text { freedom }\end{array}$ & $\begin{array}{l}\text { Average } \\
\text { squares }\end{array}$ & $\begin{array}{l}\text { Value } \\
\text { (D) }\end{array}$ & $\begin{array}{c}\text { Level of } \\
\text { significance }\end{array}$ \\
\hline \multirow{3}{*}{ Interest in the environment } & Between groups & 0.061 & 2 & 0.030 & \multirow[t]{3}{*}{0.567} & \multirow[t]{3}{*}{0.570} \\
\hline & Within groups & 4.028 & 75 & 0.054 & & \\
\hline & Total & 4.089 & 77 & & & \\
\hline \multirow{3}{*}{$\begin{array}{l}\text { Use of sustainable products } \\
\text { and solutions in interior } \\
\text { design scenarios }\end{array}$} & Between groups & 0.868 & 2 & 0.434 & \multirow[t]{3}{*}{2.448} & \multirow[t]{3}{*}{0.093} \\
\hline & Within groups & 13.294 & 75 & 0.177 & & \\
\hline & Total & 14.162 & 77 & & & \\
\hline
\end{tabular}

sustainable products and solutions in interior design scenarios were due to their year level. These results mean that the level of interest in the environment of interior design program students at KAU and the extent of their use of sustainable products and solutions in interior design scenarios vary according to the academic year.

\section{Discussion}

Several large-scale studies on sustainability and the environment were conducted, but individual responses to the different statements generally reflected more favourable attitudes towards the environment and sustainability. In the current study, the attitude level of interior design students towards environmental sustainability was determined. The mean of the environmental sustainability measurement data was 3.21 . This value was greater than the average value on the 5-degree scale, and participants' data showed that the majority of students surveyed were environmentally responsible and were likely to be very interested 
in environmental practices. Similar results have been obtained in the literature on attitudes towards sustainable environments (Ruff \& Olson, 2009; Şahin \& Erkal, 2017). These findings emphasise the importance of education in building the awareness and promoting positive behaviours of environmental sustainability as well as the inclusion of sustainable methods and products in educational methods. After analysing the numerous statements, the researcher recommends increasing support for environmental awareness and educating students about conserving environmental resources. Sustainability should be a conceptual approach with a philosophical dimension that reflects a positive means of achieving effective practices.

\section{Environmental sustainability/Ecology}

As for the number of natural resources statement (6), the degree of approval of the sample stating that "The earth has plenty of natural resources if we only learn how to develop them" obtained the highest average with a mean value of 4.86. This finding indicates that the respondents were aware of the balance needed to be achieved between the conservation of natural resources and human work. However, the degree to which the respondents agreed with the negative statement that "The balance of nature is very delicate and easily upset" was small, with a mean value of 2.46 , reflecting the awareness of students of environmental problems.

The students seemed to have very positive attitudes towards the expression of respect for nature statement (7), where the average with a mean value of the degree of approval of the sample reached 4.77. The results also showed that respondents were aware of the possibility of a disaster if things continue on their current situation, as seen in by statement (15). The results of statement (12) were examined in conjunction with the results of statement (2); surprisingly, the degree to which respondents agreed with statement (2), that "Humans have the right to modify the natural environment to suit their needs", was moderate, and the average with a mean value of 3.27 was either the degree of approval of the students for statement (12), "Humans are meant to rule over the rest of nature", or the average with a mean value of 2.00 .

Statement (1) asked for answers to "We are approaching the limit of the number of people the earth can support", and the degree of approval of the sample was moderate, with a mean value was 3.32. When the participants were asked about the negative statement (3), "When humans interfere with nature it often produces disastrous consequences", the degree of approval of this term was moderate, and the average with a mean value was 2.60 . A large segment of the respondents believe that human actions have serious consequences for nature. The degree of approval of the students who were asked "The so-called 'ecological crisis' facing humankind has been greatly exaggerated” in statement (10) was low, and the average with a mean value was 2.55 , while the negative statement "Humans are severely abusing the environment" was lower, and the mean reached 1.55 . 


\section{Environmental sustainability}

The average of the degree of approval of the sample for the terms related to the use of sustainable products and solutions in interior design scenarios was 4.12. This value was much higher than the average value of the 5-measure. The study of respondents' responses reflects the fact that for statement (20), "If I had the opportunity I would build my home using sustainable methods", the average is the same as their approval for this term (4.59). The results also show that the majority of students could complete an interior design project using sustainable methods. The average regarding the degree of approval of the respondents who believed "sustainability" should be required in the interior design program was 4.40 , reflecting a very high approval level, while the average with a mean value was 4.33 reflected the extent to which respondents believed they "could complete an interior design project using sustainable products".

The average with a mean value regarding the degree to which the students surveyed believe they can direct the client towards a sustainable career design if they are consulted was very large, while it was significant in terms of the possi-bility of "directing a client to a sustainable building in residential or commercial design". As for the degree to which students interviewed believed in statement (19), that "there is no reason that using sustainable practices in design is op-tional", it was significant and valued at 3.81. In addition, the average of those who believed in statement (24), that "knowledge justifies the added cost of sustainable features to clients", was lower, reached 3.01 and was considered medium.

\section{Comments}

In the comments section, it should be noted that the answers varied. The results indicate that respondents understand environmental sustainability and have an awareness and a sense of commitment to environmental sustainability in the future. A review of the open responses to the applications of students of the interior design of sustainable solutions in their projects revealed a gap between these and the closed responses in section (2) of the questionnaire. This result indicates a relative difference between the behaviour of respondents in using sustainable solutions in their projects and the approved attitude they have announced. In other words, there is a gap between what students think (the Environmental Sustainability section) and what they do in their design projects (Comments section). This result confirms the findings of Ruff \& Olson, who found a contradiction between what the students think they know (Environmental Sustainability section) and what they actually know (Comments section) (Ruff \& Olson, 2009).

What is the potential impact of teaching interior design on attitudes towards sustainable design? The results show that the level of environmental concerns of students of interior design at KAU, using products and sustainable solutions in interior design scenarios, is important regardless of the academic year of specialization they belong to and of their level of study. Contrary to the findings of 
Gale et al., that higher-level students have a more positive attitude towards sustainable design than lower-level students with a relationship between the two variables (Gale et al., 2014), and in contrast to the researcher's expectations, the results of the current study showed that the attitudes and perceptions of design students at KAU regarding environmental sustainability varied depending upon the year or the level of study.

\section{Conclusion and Recommendation}

In general, the attitudes of interior design students at KAU were pro-environmental, yet the answers to the various environment-related statements, which were taken separately, did not illustrate the importance of pro-environmental attitudes for all students. Although it is clear that there is a general understanding of students of problems related to nature, a lack of information accuracy was detected, in particular, through the presence of a large number of unstable responses. Therefore, the researcher recommends the need to organize workshops and conferences on environmental problems and identify these problems and the challenges that exist to overcome them.

As for the use of sustainable products and solutions in interior design scenarios, the statements of the interior design students at KAU reflect clear ideas for responsible design. Considering the multiple and diverse responses to the use of sustainable products and solutions in interior design scenarios, the results showed an understanding of the methods and products, but their application in the design of students showed significant shortcomings. In this context, the researcher recommends that the application of these methods and products be followed closely by the studio educators. They should also seek to identify and overcome the obstacles that students often face in this context. By deepening students' understanding of how to apply the fundamentals of "responsible design", they can be directed to achieve interesting results. The next generation of interior designers must be well prepared to engage in the environmental conservation system, especially as the current situation will accept no further leniency or disregard in the application of those practices.

As a study of environmentally sustainable design has not been conducted from the perspective of students in Saudi Arabia and because the country is working hard to support environmental sustainability, this study explored the levels of knowledge about environmental sustainability, cognition, attitudes and behaviour among university students.

In addition, previous research has clearly revealed the lack of studies on this topic and recommended a study of students' environmental issues, as students are the fundamental factors of change who will confront the environmental problems of current human activities.

The results of this study will help to raise awareness of interior design educators about students' attitudes towards environmental sustainability. The results also illustrate the importance of following the application of sustainability re- 
quirements in interior design projects and of not limiting student exposure.

\section{Acknowledgements}

I would like to acknowledge all of the students at the department of Interior design and Furniture in Faculty of Human Sciences and Design at King Abdul-Aziz University in Jeddah, Saudi Arabia, to give me the opportunity to apply this study. I also offer special thanks to my colleagues for their help in improving this paper.

\section{Conflicts of Interest}

The author declares no conflicts of interest regarding the publication of this paper.

\section{References}

Al-Naqbi, A. K., \& Alshannag, Q. (2018). The Status of Education for Sustainable Development and Sustainability Knowledge, Attitudes, and Behaviors of UAE University Students. International Journal of Sustainability in Higher Education, 19, 566-588. https://doi.org/10.1108/IJSHE-06-2017-0091

Bacon, L. (2011). Interior Designer's Attitudes toward Sustainable Interior Design Practices and Barriers Encountered When Using Sustainable Interior Design Practices. Lincoln, NE: University of Nebraska-Lincoln

Beery, T. (2013). Making Sustainable Behaviors the Norm at the University of Minnesota Duluth. Journal of Sustainability Education, 5, 1-16.

Bonda, P., \& Sosnowchik, K. (2006). Sustainable Commercial Interiors. New York: John Wiley \& Sons.

Brundiers, K., Wiek, A., \& Redman, C. L. (2010). Real-World Learning Opportunities in Sustainability: From Classroom into the Real World. International Journal of Sustainability in Higher Education, 11, 308-324. https://doi.org/10.1108/14676371011077540

Çeliker, A. (2017). Sustainable Housing: A Conceptual Approach. Open House International, 42, 49-57.

Council for Interior Design Accreditation (CIDA) (2019). Professional Standards 2018. http://www.accredit-id.org/professional-standards

Demirkan, H., \& Afacan, Y. (2018). Setting the Key Issues and a Prioritization Strategy for Designing Sustainable Interior Environments. METU Journal of the Faculty of Architecture, 35, 201-219. https://doi.org/10.4305/METU.JFA.2018.1.11

Dunlap, R. E., Van Liere, K. D., Mertig, A. G., \& Jones, R. E. (2000). New Trends in Measuring Environmental Attitudes: Measuring Endorsement of the New Ecological Paradigm: A Revised NEP Scale. Journal of Social Issues, 56, 425-442. https://doi.org/10.1111/0022-4537.00176

El-Zeiny, R. M. A. (2012). Sustainability in the Education of Interior Designers in Egypt. Procedia-Social and Behavioral Sciences, 38, 122-131. https://doi.org/10.1016/j.sbspro.2012.03.332

Gale, A. J., Martin, D., Martin, K., \& Duffey, M. A. (2014). The Burnout Phenomenon: A Comparative Study of Student Attitudes toward Collaborative Learning and Sustainability. Journal of Interior Design, 39, 17-31. https://doi.org/10.1111/joid.12022

Giannelloni, J. L. (1998). Les comportements liés à la protection de l'environnement et leurs déterminants: un état des recherches en marketing. Recherche et Applications en Marketing (French Edition), 13, 49-72. https://doi.org/10.1177/076737019801300204 
Harraway, J., Broughton-Ansin, F., Deaker, L., Jowett, T., \& Shephard, K. (2012). Exploring the Use of the Revised New Ecological Paradigm Scale (NEP) to Monitor the Development of Students' Ecological Worldviews. The Journal of Environmental Education, 43, 177-191. https://doi.org/10.1080/00958964.2011.634450

Hayles, C. S. (2015). Environmentally Sustainable Interior Design: A Snapshot of Current Supply of and Demand for Green, Sustainable or Fair Trade Products for Interior Design Practice. International Journal of Sustainable Built Environment, 4, 100-108. https://doi.org/10.1016/j.ijsbe.2015.03.006

Honadi, S. (2014). The Terminology of Sustainable Design and Its Relation to Social Responsibility as Interior Designer. Unpublished Manuscript, Raffles Design Institute Guangzhou /Sustainable Design (DN022).

https://www.academia.edu/11355826/The Terminology of Sustainable Design and I ts Relation to Social Responsibility as Interior Designer

Kang, M., \& Guerin, D. A. (2009). The Characteristics of Interior Designers Who Practice Environmentally Sustainable Interior Design. Environment and Behavior, 41, 170-184. https://doi.org/10.1177/0013916508317333

Khaleel, E. A. S. E. S. (2013). Towards a Sustainable Interior Design of the Commercial Buildings in Gaza: Framework of Environmental Assessment Index.

Mate, K. (2009). Attitudes versus Actions: Are Interior Designers Genuinely Embracing Sustainable Design through Material Selection? In 5th International Conference of the Association of Architecture Schools in Australasia (pp. 1-9).

McCoy, J. (2012). Sustainability: Environmentally Responsible Interior Design. Journal of Interior Design, 37, 5-6. https://doi.org/10.1111/j.1939-1668.2011.01070.x

Paço, A., \& Lavrador, T. (2017). Environmental Knowledge and Attitudes and Behaviours towards Energy Consumption. Journal of Environmental Management, 197, 384-392. https://doi.org/10.1016/j.jenvman.2017.03.100

Polonsky, M. J., Garma, R., \& Landreth Grau, S. (2011). Western Consumers' Understanding of Carbon Offsets and Its Relationship to Behavior. Asia Pacific journal of marketing and logistics, 23, 583-603. https://doi.org/10.1108/13555851111183048

Rider, T. (2005). Education, Environmental Attitudes and the Design Profession. Master's Thesis.

Ruff, C. L., \& Olson, M. A. (2009). The Attitudes of Interior Design Students towards Sustainability. International Journal of Technology and Design Education, 19, 67-77. https://doi.org/10.1007/s10798-007-9038-0

Şahin, H., \& Erkal, S. (2017). An Investigation of University Students' Attitudes toward Environmental Sustainability. European Journal of Sustainable Development, 6, 147-154.

Summers, M., Kruger, C., Childs, A., \& Mant, J. (2000). Primary School Teachers' Understanding of Environmental Issues: An Interview Study. Environmental Education Research, 6, 293-312. https://doi.org/10.1080/713664700

Winchip, S. M. (2007). Sustainable Design for Interior Environments Second Edition. London: A \& C Black. 